\title{
Thin-Film Gas Sensors Operating in a Perpendicular Current Mode
}

\author{
Yurie Ishikawa, Kazuhiro Hara \\ Tokyo Denki University, 5 Senju-Asahi-cho, \\ Adachi-ku, Tokyo 120-8551 Japan \\ hara@eee.dendai.ac.jp
}

\begin{abstract}
Thin-film gas sensors operating in a perpendicular current mode are presented. To achieve this mode, a mesh-like top electrode is deposited on a sensing film instead of an electrode that is normally deposited on a substrate. The sensor current flows perpendicularly to the surface of the thin film and thus is not blocked by the cracks that are generated by an annealing process after deposition and by the difference of the thermal expansion coefficients between the sensing film and the substrate. The sensor is expected to work for a longer period of time without possible deterioration caused by cracks. Moreover, the mesh-like top electrode enhances the sensitivity to hydrogen by acting as a catalyst when Pt is used for the top electrode.
\end{abstract}

Key words: hydrogen sensor, thin film, metal oxide, cracks, perpendicular current mode

\section{Introduction}

Thin-film gas sensors tend to deteriorate with an increase in cracks for $\mathrm{SnO}_{2}$-based [1][2] and $\mathrm{WO}_{3}$-based films[3]. These cracks are usually generated perpendicular to the surface of the sensing film by the difference of the thermal expansion coefficients between the sensing film and the substrate.

Some cracks are also generated by an annealing process after deposition that is usually carried out for the recovery from various defects and the stabilization of the crystal structure. In this process metal-oxide films generally shrink as a consequence of sintering while its substrate usually expands as a consequence of thermal expansion. During an annealing process, the internal stress in the film increases and then cracks are generated to release the internal stress.

The current flow in the sensing film is schematically shown in Fig.1 for a traditional thin-film gas sensor operating in a parallel current mode. The sensor current is apparently blocked by the cracks. The increase in the number of cracks decreases the sensor current and thus its electrical conductance.

In this paper some examples of cracks observed by SEM are shown for a variety of sensor materials. Then a novel thin-film gas sensor that reduces the adverse effect of cracks is proposed. In this sensor the top electrode is deposited on the sensing film in order to change the current direction as shown in Fig.2. The current flows perpendicularly to the surface from the bottom electrode to the top electrode without the adverse effects caused by the cracks.

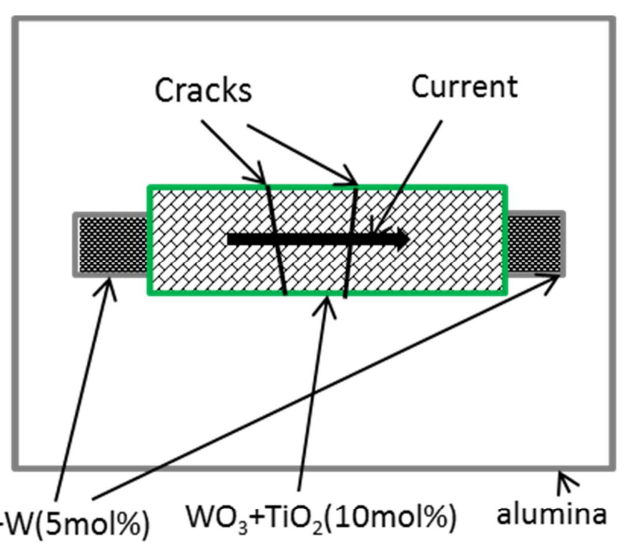

(a)Top view

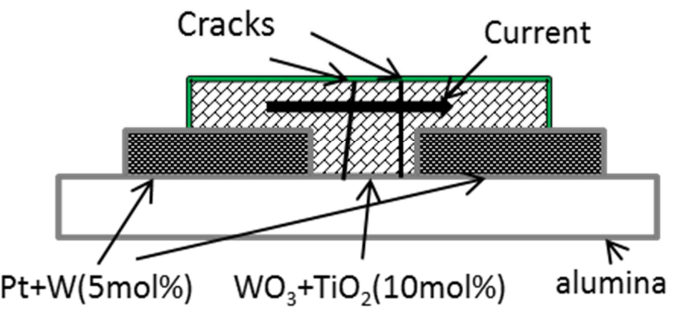

(b)Cross-sectional view

Fig.1 Traditional thin-film gas sensor operating in a parallel current mode. 


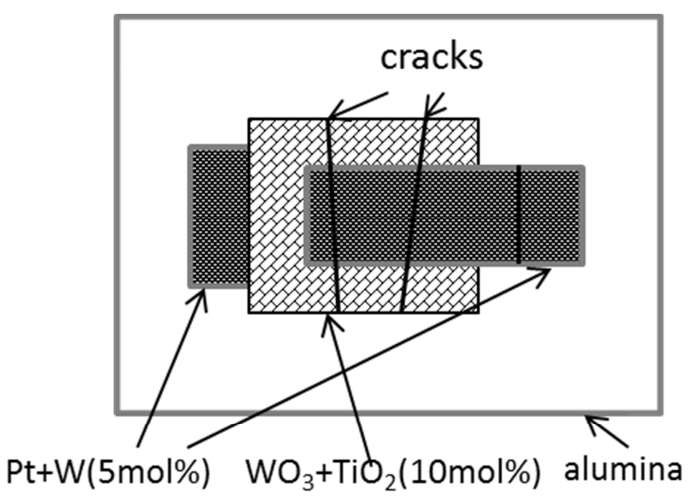

(a)Top view

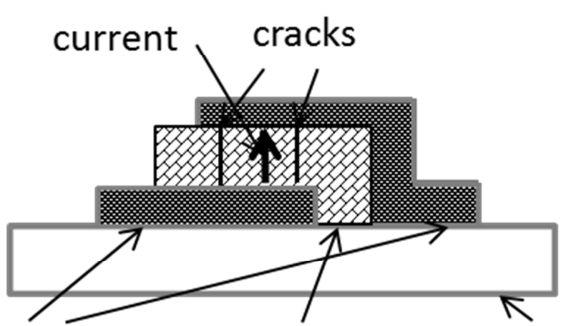

$\mathrm{Pt}+\mathrm{W}(5 \mathrm{~mol} \%) \quad \mathrm{WO}_{3}+\mathrm{TiO}_{2}(10 \mathrm{~mol} \%)$ alumina

(b)Cross-sectional view

Fig.2 Proposed thin-film gas sensor operating in a perpendicular current mode.

\section{Sensor fabrication}

All films in Fig. 2 were successively deposited on an alumina substrate by r.f. sputtering. The thickness of the bottom Pt-based film, the $\mathrm{WO}_{3}$ based film and the top Pt-based film was $200 \mathrm{~nm}, 100 \mathrm{~nm}$ and $10 \mathrm{~nm}$, respectively. The sensor geometry was defined by photolithography. Sensors with $\mathrm{SnO}_{2}-$ based $\left(\mathrm{SnO}_{2}+\mathrm{Pd}(4 \mathrm{~mol} \%)+\mathrm{V}_{2} \mathrm{O}_{5}(4 \mathrm{~mol} \%)\right)$,

$\mathrm{Fe}_{2} \mathrm{O}_{3}$-based $\left(\mathrm{Fe}_{2} \mathrm{O}_{3}+\mathrm{TiO}_{2}(5 \mathrm{~mol} \%)+\mathrm{MgO}(4 \mathrm{~mol} \%)\right)$, $\mathrm{NiO}$ and $\mathrm{TiO}_{2}$ thin-films were also fabricated.

\section{Cracks in thin-films for various materials}

Figure 3 shows the surface morphology of a $\mathrm{SnO}_{2}$-based film. This film was annealed at $600^{\circ} \mathrm{C}$ in air soon after deposition. Two cracks are clearly observed.

Figure 4 shows the surface morphology of a NiO-based film. This film was annealed at $1000{ }^{\circ} \mathrm{C}$ in air after deposition. A crack is observed in addition to the crystal growth of the grains.

Figure 5 shows the surface morphology of a $\mathrm{WO}_{3}$-based film. This film was heated at $420^{\circ} \mathrm{C}$ for 4 months after annealing at $600^{\circ} \mathrm{C}$ in air. Several cracks are also observed in addition to a structural irregularity of the morphology.

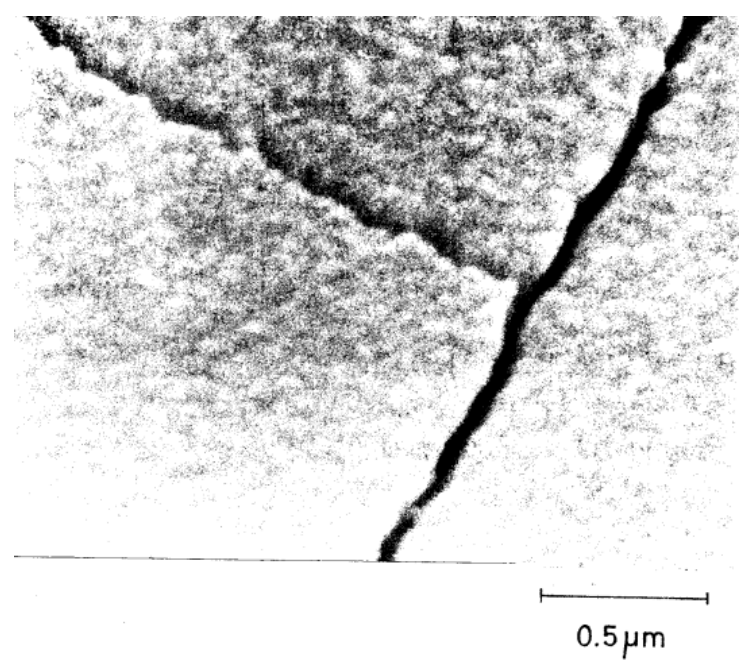

Fig. 3 Surface morphology of a $\mathrm{SnO}_{2}$-based film after being annealed at $600^{\circ} \mathrm{C}$.

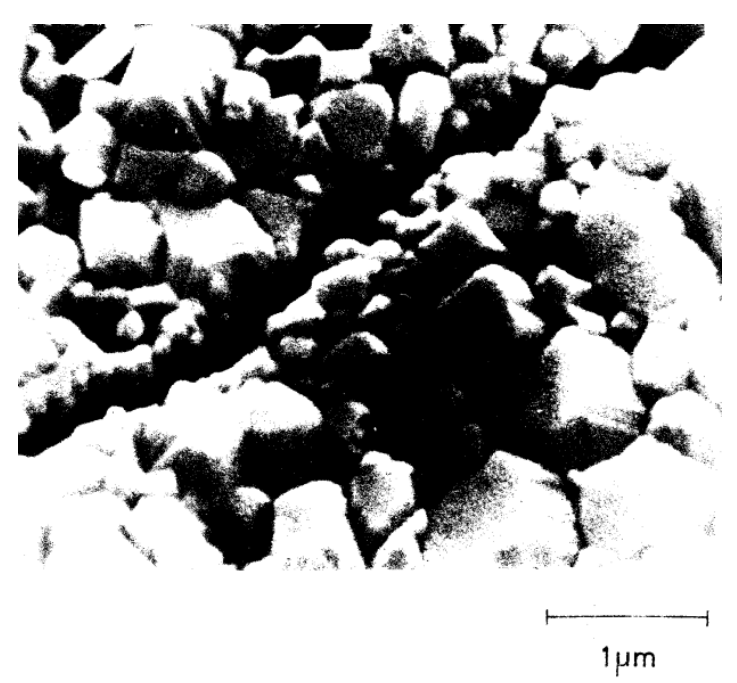

Fig. 4 Surface morphology of a NiO-based film after being annealed at $1000^{\circ} \mathrm{C}$.

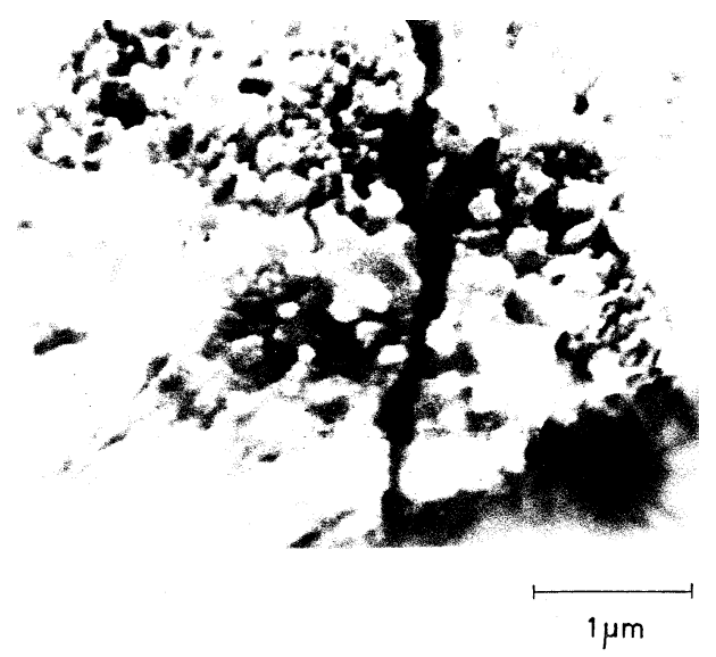

Fig. 5 Surface morphology of a $\mathrm{WO}_{3}$-based film after operating at $420^{\circ} \mathrm{C}$ for 4 months. 
$\mathrm{WO}_{3}$-based film peeled off from the substrate when it was annealed at a temperature higher than $600^{\circ} \mathrm{C}$.

Figure 6 shows the surface morphology of a $\mathrm{TiO}_{2}$-based film. This film was heated at $420^{\circ} \mathrm{C}$ for 4 months after annealing at $600^{\circ} \mathrm{C}$ in air. Several cracks are also observed.

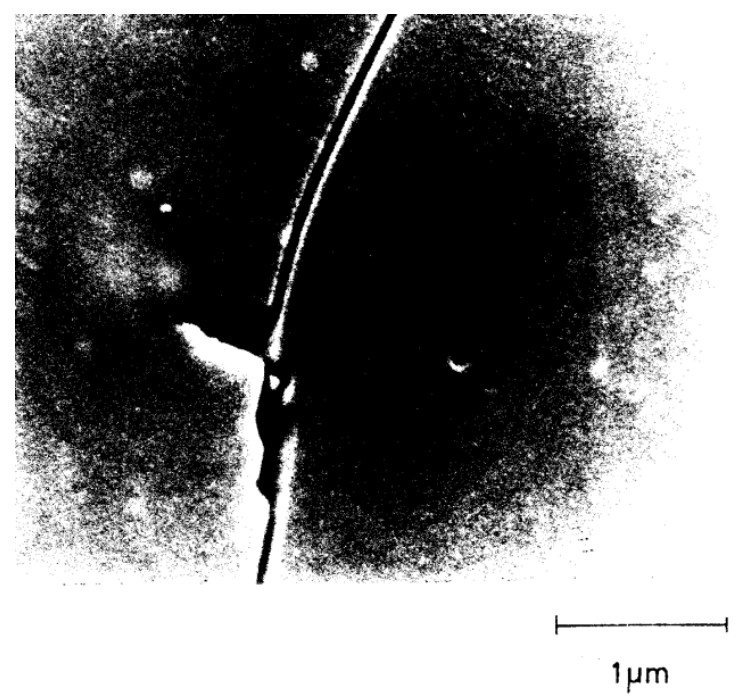

Fig. 6 Surface morphology of a $\mathrm{TiO}_{2}$-based film after operating at $420^{\circ} \mathrm{C}$ for 4 months.

\section{Sensing characteristics and discussion}

$\mathrm{WO}_{3}$-based, $\mathrm{SnO}_{2}$-based and $\mathrm{Fe}_{2} \mathrm{O}_{3}$-based thin-film sensors were tested at 3000 ppm of hydrogen gas. Figure 7 shows the temperature dependence of the sensitivity to hydrogen for these sensors. Here the sensitivity is defined as the ratio of the resistance in air to that in gas. The $\mathrm{WO}_{3}$-based sensor shows considerably high sensitivity to hydrogen in the lower temperature range near $100^{\circ} \mathrm{C}$ though $\mathrm{SnO}_{2}-$ based and $\mathrm{Fe}_{2} \mathrm{O}_{3}$-based thin-film sensors are also sensitive to hydrogen gas.

The dependence of the sensitivity on hydrogen concentration is shown in Fig. 8 for a $\mathrm{WO}_{3}$ based sensor. The sensor was capable of detecting hydrogen at a concentration as low as 100ppm.

The sensitivity to various gases is shown in Fig.9. The $\mathrm{WO}_{3}$-based sensor was sensitive to hydrogen gas among various gases. Thus the selectivity to hydrogen gas was quite good.

As for the sensors with $\mathrm{SnO}_{2}$-based film, longterm stability was examined. A traditional sensor operating in a parallel current mode degraded gradually and its conductance gradually decreased. In contrast, our novel sensor operating in a perpendicular current mode underwent less change.

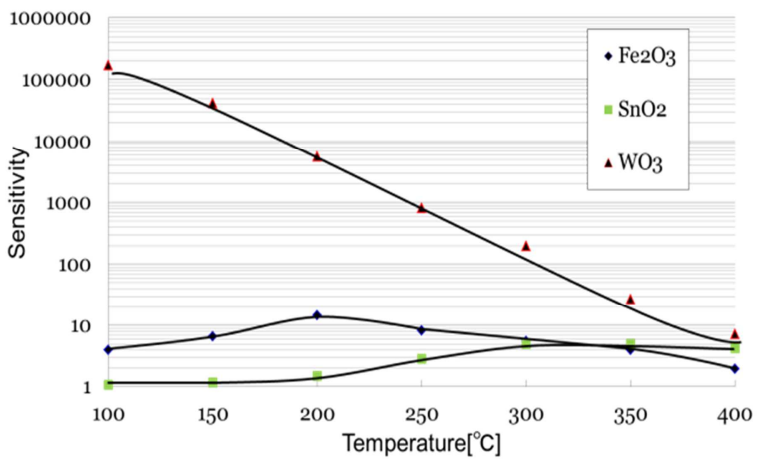

Fig.7 Temperature dependence of the sensitivity to hydrogen for $\mathrm{WO}_{3}$-based, $\mathrm{SnO}_{2}$ based and $\mathrm{Fe}_{2} \mathrm{O}_{3}$-based thin-film sensors. Hydrogen concentration is $3000 \mathrm{ppm}$.

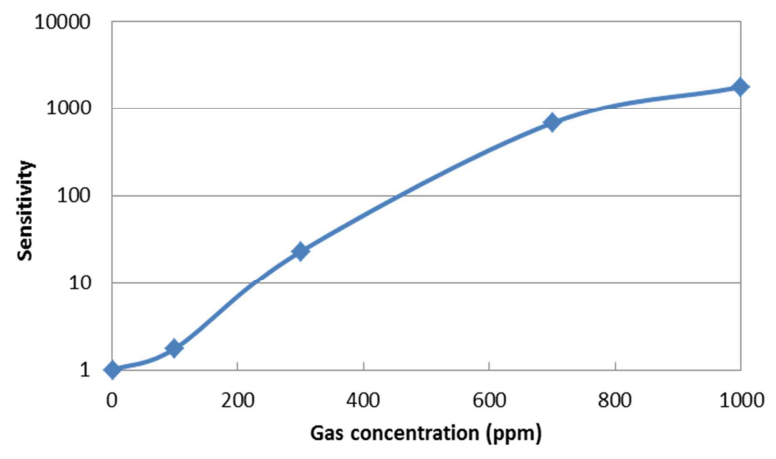

Fig.8 Dependence of the sensitivity on hydrogen concentration for $\mathrm{WO}_{3}$-based sensor at an operating temperature of $150^{\circ} \mathrm{C}$.

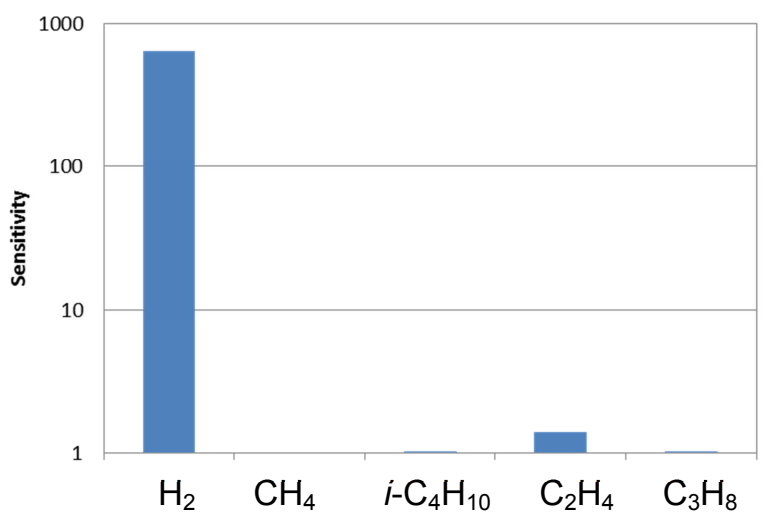

Fig. 9 Sensitivity to various gases for $\mathrm{WO}_{3}$ based sensor at an operating temperature of $150^{\circ} \mathrm{C}$.

The transient response for $\mathrm{WO}_{3}$-based sensors is shown in Fig. 10 and 11 , at an operating temperature of $100^{\circ} \mathrm{C}$ and $150^{\circ} \mathrm{C}$, respectively.

The response time and recovery time that are taken at the time for the resistance to reach $90 \%$ of the change are $1 \mathrm{sec}$ and $22 \mathrm{~min}$, respectively at $100{ }^{\circ} \mathrm{C}$. The recovery time is quite long while the response time is short. 
The response time and recovery time are $22 \mathrm{sec}$ and $2 \mathrm{~min}$, respectively at $150^{\circ} \mathrm{C}$. The recovery time is much short compared that at $100^{\circ} \mathrm{C}$.

The thickness of the top electrode $\mathrm{Pt}$ was adjusted so that the film was mesh-like. Hydrogen gases adsorb on the surface of the sensing film that is not covered by Pt while they are activated by the catalytic action of $\mathrm{Pt}$ that exists nearby. Thus the sensitivity and selectivity to hydrogen are enhanced.

The temperature dependence of the sensitivity to hydrogen for 2 kinds of $\mathrm{Fe}_{2} \mathrm{O}_{3}$-based sensors with differnt thicknesses of the top electrode is shown in Fig. 12.

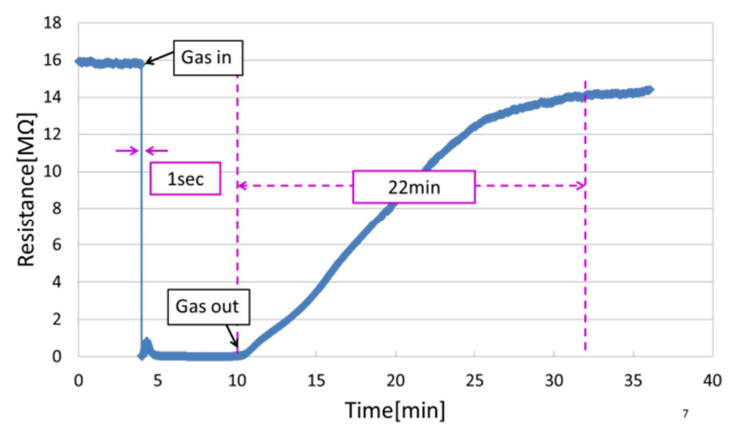

Fig.10 The transient response for $\mathrm{WO}_{3}$-based sensor at an operating temperature of $100^{\circ} \mathrm{C}$.

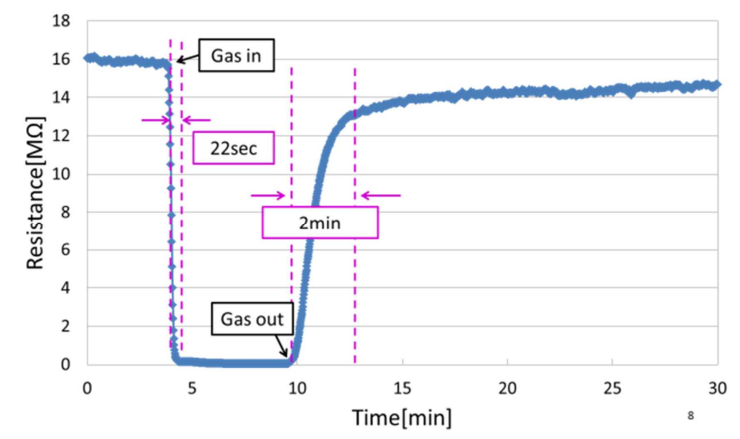

Fig.11 The transient response for $\mathrm{WO}_{3}$-based sensor at an operating temperature of $150^{\circ} \mathrm{C}$.

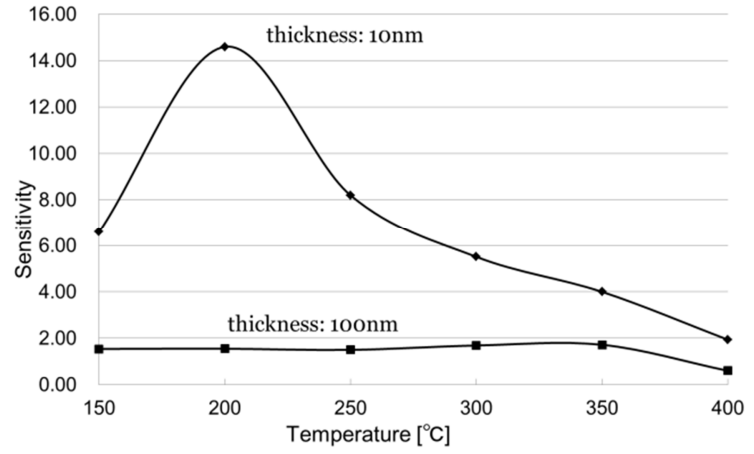

Fig. 12. Temperature dependence of the sensitivity to hydrogen for $\mathrm{Fe}_{2} \mathrm{O}_{3}$-based sensors with different thicknesses of the top electrode: $10 \mathrm{~nm}$ and $100 \mathrm{~nm}$.

When the thickness of the top electrode was $100 \mathrm{~nm}$, the sensitivity to hydrogen was low. In this sensor the surface of the sensing film was fully covered by the top electrode and thus there were no sites for hydrogen to adsorb. This is the reason for low sensitivity to hydrogen.

\section{Conclusion}

Thin-film gas sensors operating in a perpendicular current mode are presented. The sensor current flows perpendicularly to the surface of the thin film and thus is not blocked by the cracks. The sensors are expected to work for a longer period of time without possible deterioration caused by the cracks. Moreover, when $\mathrm{Pt}$ is used for the top electrode, by acting as a catalyst the sensitivity to hydrogen is enhanced.

\section{References}

[1] J. Yu, Z.A. Tang, G.Z. Yan, P.C.H. Chan, Z.X. Huang, Sensors and Actuators B 139, 346-352 (2009); doi: 10.1016/j.snb.2009.03.033

[2] R.K. Sharma, P.C.H. Chan, Z. Tang, G. Yan, I.-M. Hsing, Sensors and Actuators B 81, 9-16 (2001).

[3] T. S. Kim, Y. B. Kim, K. S. Yoo, G. S. Sung, H.J. Jung, Sensors and Actuators B 62, 102-108 (2000). 